Article

\title{
Analysis of Kaolin Flocculation in Seawater by Optical Backscattering Measurements: Effect of Flocculant Management and Liquor Conditions
}

\author{
Ricardo I. Jeldres $1, *\left(\mathbb{D}\right.$, Matías Jeldres ${ }^{1,2}$, Michael R. MacIver ${ }^{3}$, Marek Pawlik ${ }^{3}$, Pedro Robles ${ }^{4}$ \\ and Norman Toro ${ }^{5, *}$ \\ 1 Departamento de Ingeniería Química y Procesos de Minerales, Facultad de Ingeniería, Universidad de \\ Antofagasta, 1240000 Antofagasta, Chile; hujeldres@unap.cl \\ 2 Faculty of Engineering and Architecture, Universidad Arturo Prat, Almirante Juan José Latorre 2901, \\ 1240000 Antofagasta, Chile \\ 3 Norman B. Keevil Institute of Mining Engineering, The University of British Columbia, 517-6350 Stores \\ Road, Vancouver, BC V6T 1Z4, Canada; rmcmaciver@hotmail.com (M.R.M.); mpp@mining.ubc.ca (M.P.) \\ 4 Escuela de Ingeniería Química, Pontificia Universidad Católica de Valparaíso, 2340000 Valparaíso, Chile; \\ pedro.robles@pucv.cl \\ 5 Departamento de Ingeniería Metalúrgica y Minas, Universidad Católica del Norte, Av. Angamos 610, \\ 1270709 Antofagasta, Chile \\ * Correspondence: Ricardo.jeldres@uantof.cl (R.I.J.); ntoro@ucn.cl (N.T.); \\ Tel.: +56-552-637-901 (R.I.J.); +56-552-651-021 (N.T.)
}

Received: 16 February 2020; Accepted: 28 March 2020; Published: 31 March 2020

\begin{abstract}
Optical backscattering (OBS) signal values were used to evaluate the flocculation of kaolin slurries and seek the implications of using seawater. Two anionic flocculants were applied to kaolin suspensions at several dosages and in water of varying $\mathrm{pH}$ and electrolyte concentration. An OBS height scan method was used to estimate the degree of aggregation, supernatant quality, and solids concentration of the sediments. The residual solids of the supernatant depended of the extent of particle coagulation before flocculant was added, where the $\mathrm{pH}$ and salinity displayed a significant impact on flocculation. The OBS results were highly sensitive to the presence of fine particles, which was estimated in parallel from the focused beam reflectance measurements (FBRM.) In seawater, without flocculant added, the samples had increased root-mean-square scattering $\left(\mathrm{F}_{\mathrm{rms}}\right)$ values and larger final sediment volume than samples prepared in water with lower electrolyte concentration. This indicates a higher initial state of aggregation of the particles in seawater. Then, the aggregation degree was best linked to the square-weighted chord length distribution of the FBRM data, which intensifies the sensitivity to coarse aggregates.
\end{abstract}

Keywords: clays; seawater flocculation; optical backscattering; aggregation state; polyelectrolyte

\section{Introduction}

The flocculation of mineral particles is a critical treatment step for mining tailings in thickening operations, where the goal is to recover water through gravity thickeners and recycle it to upstream operations [1,2]. Water recovery is especially important in arid regions, far from the coast or at high altitudes, where there is decreased water availability or when the production of freshwater requires the construction of reverse osmosis plants to desalinate seawater [3-5]. The direct use of seawater in dewatering circuits may be an attractive option, but particle flocculation in a saline environment remains a challenge. 
In seawater, the high ionic strength reduces the electrostatic forces and causes a change in the water structure [6,7]. Whereas little information is available on the impact of seawater in the gravity thickening process, there is ample evidence of the influence of salinity on the flocculation mechanisms [8-10]. For example, Costine et al. [11] analyzed continuous flocculation of kaolin sludge with anionic polyacrylamides of varying molecular weights. Continuous flocculation was achieved in a Couette mixer with a vertical flow arrangement, which allows the settling rate to be measured independently of the operator under controlled mixing conditions. The authors found that at low sodium chloride concentration $(<0.01 \mathrm{M})$, the coagulation of particles was promoted, thereby reducing the polymer doses required to reach the target settlement rate. All the flocculants studied were negatively affected by the increase in calcium concentrations in the suspensions, with the effects of reduced bridge capacity being particularly evident in lower molecular weight (MW) flocculants.

In a study of the effects of salinity on kaolin flocculation, Jeldres et al. [12] found that increased salinity caused an increase in the competitive effects for the general flocculation mechanism. Improved polyelectrolyte adsorption on the kaolin surface promotes aggregation by increasing the efficiency of particle-particle collisions, but salinity reduces the radius of gyration of the polyelectrolyte, which limits the overall aggregate size. This phenomenon was later demonstrated by through molecular dynamics simulations [13]. Recently, Jeldres et al. [14] proposed a strategy to improve flocculation efficiency in seawater by reducing the magnesium content of the seawater before introducing it to the process. It was suggested that the flocculation response was improved when the magnesium concentration was reduced because an increase in bridging flocculation between the particles was possible.

The evaluation of flocculation performance implies the measurement of some property of the suspension or supernatant after the addition of the flocculant. In a dewatering application, it is typically desirable to form aggregates that settle rapidly and form a bed that is sufficiently permeable to permit fluid upflow. This implies that the measurement of floc and mudline settling curves are relevant methods of evaluating flocculation effectiveness [15]. The measurement of supernatant turbidity has long been used to evaluate the extent of flocculation, but the relationship between turbidity of the supernatant and the properties of the aggregates is not well defined [16]. A recent work has improved upon acoustic backscatter technology for solids concentration measurement using an ultrasonic backscatter instrument with a transducer array to generate concentration profiles for a large-scale horizontal sedimentation tank [17]. Floc chord length distributions, measured with the focused beam reflectance measurement technique (FBRM), are useful for evaluating flocculation or aggregation in flowing suspensions [18]. Optical backscattering (OBS) height scans are another means of evaluating the aggregation state of a relatively stable suspension of high solids concentration [19].

OBS instruments are used in various scientific and technical fields and are based on the same basic principle: A light source is projected through a suspension to measure the reflectance with a photodetector at a specific angle [20]. In general, the OBS is used for the relative measurement of suspended solids, although a detailed analysis of the size and quantity of suspended solids is possible with calibration [21]. OBS sensor calibration is required because the shape of the particles, the surface roughness, the degree of flocculation, and the refractive index affect the optical backscatter response [22]. In a sediment bed of flocculated mineral aggregates, there are spatial variations in the solids concentration in the order of microns to millimeters. The local solids concentration goes to zero between the aggregates, while the fractal mass scale [23] of flocculated sediments causes the aggregates to have a denser center and a decreased density toward their boundaries. When an OBS scan of such a sediment is made, the local solids concentration variations produce an oscillation in the OBS signal, which is caused by a change in the path length of the photons between the scattered and the detector. The extent of the OBS oscillation depends on the wavelength of the incident light and the size of the aggregates relative to the size of the sensor aperture.

To date, several studies have analyzed the effect of a saline environment on clay flocculation [24,25], but few reports have systematically examined the impact of seawater on clay particle aggregation [26-29]. In this study, kaolin was flocculated in freshwater and seawater with two anionic high molecular 
weight polyacrylamides of different electrical charges. The results were explained in terms of the changes in the electrical interaction between surfaces of the clay particles that occurred when the $\mathrm{pH}$ and electrolyte concentration was modified. The OBS response was used to assess the kaolin flocculation, focusing on the aggregation state and sediment concentration.

\section{Methodology}

\subsection{Materials}

A sample of kaolin was obtained from Ward's Science (Rochester, NY, USA). A detailed analysis was performed to determine the mineralogical composition and chemical composition of the main functional surface groups. X-ray diffraction (Siemens D500 (Munich, Germany) with TOPAS software) indicated the kaolin sample contained $84 \mathrm{wt}$. \% of kaolinite $\left(\mathrm{Al}_{2} \mathrm{Si}_{2} \mathrm{O}_{5}(\mathrm{OH})_{4}\right)$ and $16 \mathrm{wt}$. \% of halloysite $\left(\mathrm{Al}_{2} \mathrm{Si}_{2} \mathrm{O}_{5}(\mathrm{OH})_{4} \cdot 2 \mathrm{H}_{2} \mathrm{O}\right)$ (Figure 1). Fourier transform infrared (FTIR) spectra of the mineral sample (Figure 2) showed peaks and bands characteristic of the kaolinite mineral. Three absorption bands at $3696 \mathrm{~cm}^{-1}, 3654 \mathrm{~cm}^{-1}$, and $3621 \mathrm{~cm}^{-1}$, caused by the $\mathrm{OH}$ stretching of inner-surface hydroxyl groups, indicated a high structural order of the samples. Si-O stretching bands occurred at $1115 \mathrm{~cm}^{-1}$, $1032 \mathrm{~cm}^{-1}$, and $1009 \mathrm{~cm}^{-1}$; Al-O-Si deformation appeared at $539 \mathrm{~cm}^{-1}$; Si-O-Si deformation occurred at $471 \mathrm{~cm}^{-1}$; and Si-O deformation was observable at $431 \mathrm{~cm}^{-1}$.

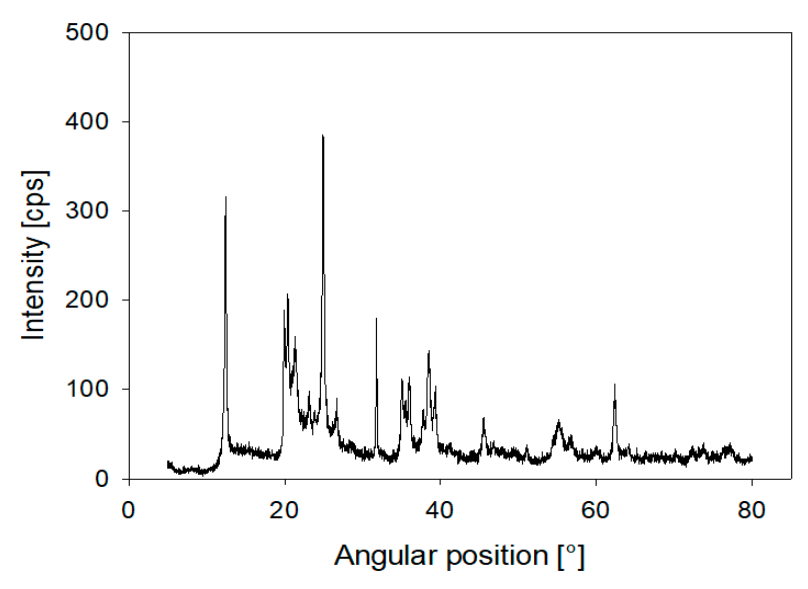

Figure 1. X-ray diffraction (XRD) for kaolin powder.

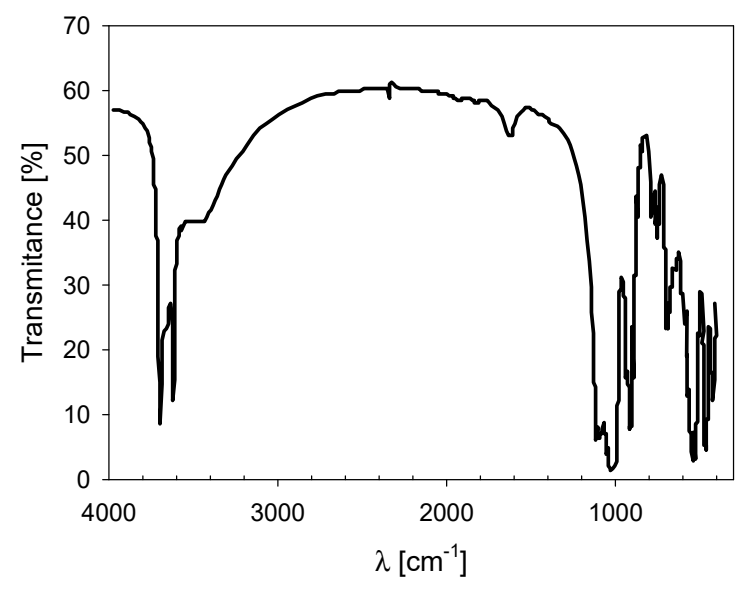

Figure 2. Fourier transform infrared (FTIR) spectrum for kaolin powder.

Particle size analysis by laser diffraction (Microtrac S3500, MICROTRAC MRB, Montgomeryville, PA, USA) indicated that the average particle size of the kaolin sample was $13 \mu \mathrm{m}$. The sample also contained a population of submicron-sized particles, as seen in Figure 3 and the SEM micrograph 
shown in Figure 4. The crystallographic structure of kaolinite consists of a tetrahedral silica surface and an aluminum hydroxide octahedral surface corresponding to the 001 basal plane. Broken covalent bonds produce the edges, and the basal faces are ionizable in aqueous solutions [30]. The kaolin plate-like morphology can be recognized in Figure 4 through the SEM images.

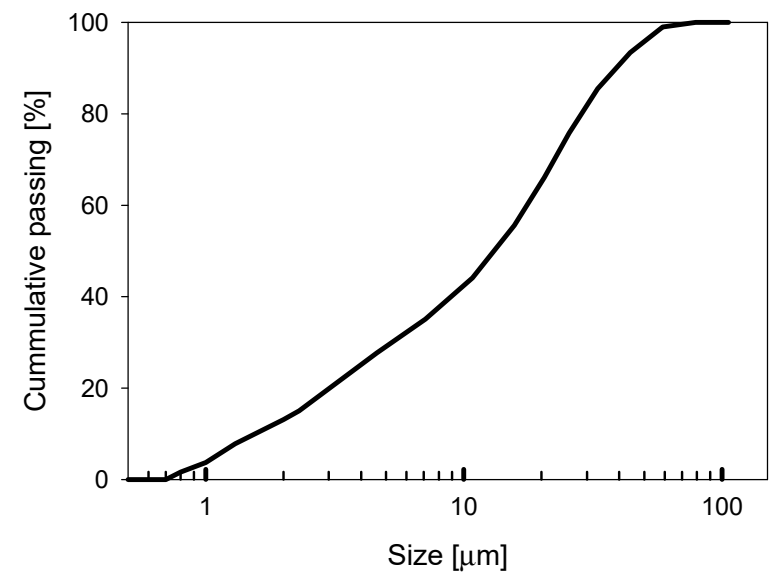

Figure 3. Particle size distribution of kaolin particles.

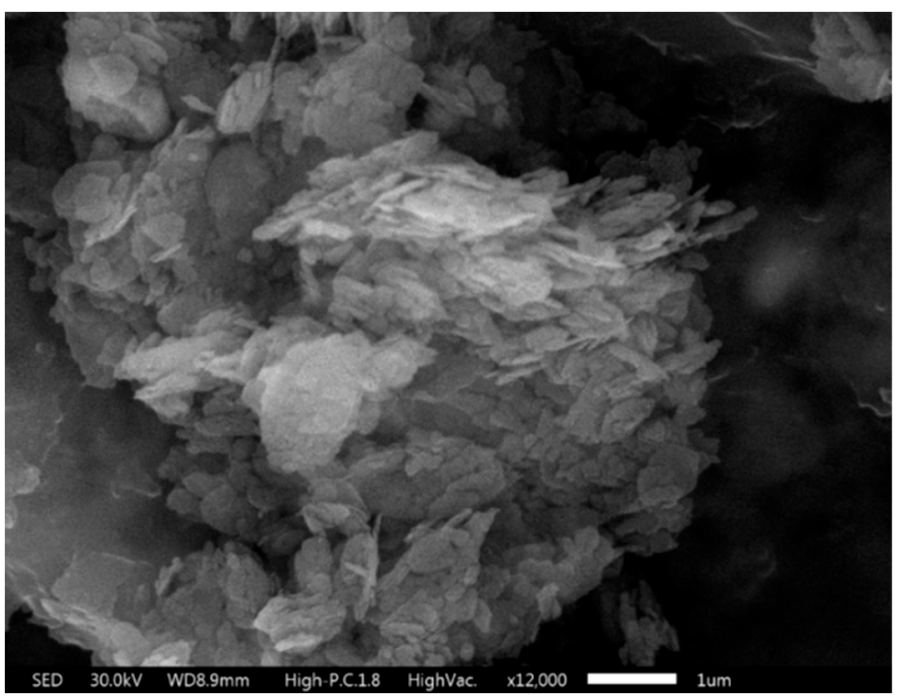

Figure 4. High-resolution SEM image showing surfaces of kaolin mineral.

Seawater was filtered at $1 \mu \mathrm{m}$ with a UV filter system to eliminate bacterial activity. The cation concentrations were determined by atomic absorption spectrophotometry: $\mathrm{Na}^{+}: 10.4 \mathrm{~g} / \mathrm{L} ; \mathrm{Mg}^{2+}$ : $1.38 \mathrm{~g} / \mathrm{L} ; \mathrm{Ca}^{2+}: 0.41 \mathrm{~g} / \mathrm{L} ; \mathrm{K}^{+}: 0.38 \mathrm{~g} / \mathrm{L}$. Using the argentometric method, the $\mathrm{Cl}^{-}$concentration was $18.7 \mathrm{~g} / \mathrm{L}$. Using acid-base volumetry, $\mathrm{HCO}_{3}{ }^{-}$was found to be $0.13 \mathrm{mg} / \mathrm{L}$.

\subsection{Aggregate Characterisation}

Focused beam reflectance measurements (FBRM) is a measurement technique used to measure and monitor the formation and evolution of aggregate size in real time. The FBRM (Particle Track E25) consists of a processing unit and a probe with a rotating lens. The lens produces a laser beam focused on the outer surface of a sapphire window (diameter: $14 \mathrm{~mm}$ ), which scans a circular path at a fixed speed. A chord length distribution may be calculated from the measured backscattering pattern based on the time duration of elevated backscattered light intensity and the laser velocity [31]. Kaolin suspensions were prepared at $7 \mathrm{wt}$. \% solids concentration and stirred at $400 \mathrm{rpm}$ in a vessel overnight to promote high particle dispersion. Then, the mixing rate was lowered to $115 \mathrm{rpm}$. The FBRM probe 
was introduced into the suspension and submerged vertically in the vessel at $10 \mathrm{~mm}$ above the agitator and $20 \mathrm{~mm}$ away from the shaft.

\subsection{Zeta Potential}

The zeta potential of the particles was measured in a Zetameter System 4.0 (Zeta-meter, Staunton, VA, USA) following the methodology of Jeldres et al. [7]. For this purpose, a diluted suspension of the mineral ( 0.1 wt. \%) was prepared, and the $\mathrm{pH}$ was adjusted with $\mathrm{HCl}$ or $\mathrm{NaOH}$, as appropriate.

\subsection{Flocculation Assays}

For OBS height scan measurements, batch flocculation of kaolin suspensions and sedimentation were carried out in 30-mL sample containers. Varied doses of two anionic polyacrylamides (PAM) of high molecular weight (A150 HMW and A100) with different degrees of anionicity (DA) were used. In this case, the DA was 7\% for A100 and 50\% for A150 HMW [32].

A stock solution of PAM of $1 \mathrm{~g} / \mathrm{L}$ was prepared by adding $0.2 \mathrm{~g}$ of each polymer with $200 \mathrm{~mL}$ of distilled water and stirring at room temperature at $375 \mathrm{rpm}$ for $4 \mathrm{~h}$. Once a day, a flocculant aliquot of the polymer solution was diluted at $0.1 \mathrm{~g} / \mathrm{L}(0.01 \mathrm{wt}$. \%) for use in daily tests. The kaolin stock suspensions were made at 7 wt. \%, at pH 5.7 in $0.01 \mathrm{M} \mathrm{NaCl}$; at pH 7.5 in $0.01 \mathrm{M} \mathrm{NaCl}$; and at pH 7.5 in seawater. In the first two cases, sodium chloride was incorporated to emulate the ionic strength of industrial freshwater. The suspension was stirred overnight to avoid particle agglomeration. A 25-g sample was extracted with a syringe equipped with a large caliber polytetrafluoroethylene (PTFE) tip while the suspension was stirred at $250 \mathrm{rpm}$. The sample was vigorously stirred for $30 \mathrm{~s}$ before applying the polymer dose, which varied between $0-115 \mathrm{~g} / \mathrm{t}$. The polymer was dosed with a syringe using the required volume of the stock solution and then completing the remainder of a total of $2 \mathrm{~mL}$ with the specific background solution to ensure that the solid concentration is consistent for each sample. The polymer dose was injected into the cell that was gently inverted ten times. After a settling period of $2.5 \mathrm{~h}$, optical scans of backscatter height were recorded as described in Section 2.5.

\subsection{Backscattering Scan}

The optical backscattering scans of flocculated particles sediments were measured with a Turbiscan MA 2000 optical analyzer (Formulation, Toulouse, France). The Turbiscan tests the transmission and backscatter light flow based on the height in a sample cell (volume: $30 \mathrm{~mL}$, height: $60 \mathrm{~mm}$ ). Following the methodology proposed by MacIver and Pawlik [19], the OBS height scan data, F(h), was analyzed to describe the degree of flocculation. Each height scan, $\mathrm{F}(\mathrm{h})$, has several features. In the portion of the $\mathrm{F}(\mathrm{h})$ scan that corresponds to the sediment, there is a mean value of OBS, $\mathrm{F}_{\text {mean }}(\%)$, and an oscillation about the mean, $\mathrm{F}_{\mathrm{rms}}(\%)$, which corresponds to the aggregation state of the sediment. In many samples, an abrupt transition in the OBS values occurs at the sediment-supernatant interface, which can be measured to accurately determine the height of the sediment bed. The final sediment height was used to calculate the concentration of sediment solids based on the known height-mass ratio within the sample vessel. The mean value of the OBS signal in the supernatant was also recorded to analyze trends in the solids concentration of the supernatant.

\section{Results and Discussions}

The OBS response was used to assess the kaolin flocculation in freshwater and seawater with two anionic polyacrylamides of high molecular weight of different charge. Then, the degree of flocculation was related to the characteristics of the sediment, such as the solid concentration and volume. The results were explained in terms of the changes in the electrical interaction (zeta potential) of the clay surfaces that occurred when the $\mathrm{pH}$ and electrolyte concentration were modified. The initial particle aggregation (flocculant free environment) was compared with the chord length measurements, which were obtained using the FBRM probe. 


\subsection{Aggregation of Primary Particles}

The FBRM was used to assess the coagulation of primary particles in freshwater and seawater without the addition of flocculant. The FBRM can be applied across a wide range of solids concentrations values and allows the in-situ measurement of aggregation extent. Figure 5 shows the chord length distributions (CLD) for the kaolin slurry at $\mathrm{pH} 7.5$ in both distilled water (DW) and seawater (SW). The unweighted distributions (Figure 5A) indicate the total number of particles and emphasize the fine particle; while the square-weighted distributions (Figure 5B) reflect a volume-weighting, which emphasized the contribution of the larger aggregates to the overall volume of aggregates formed [33].
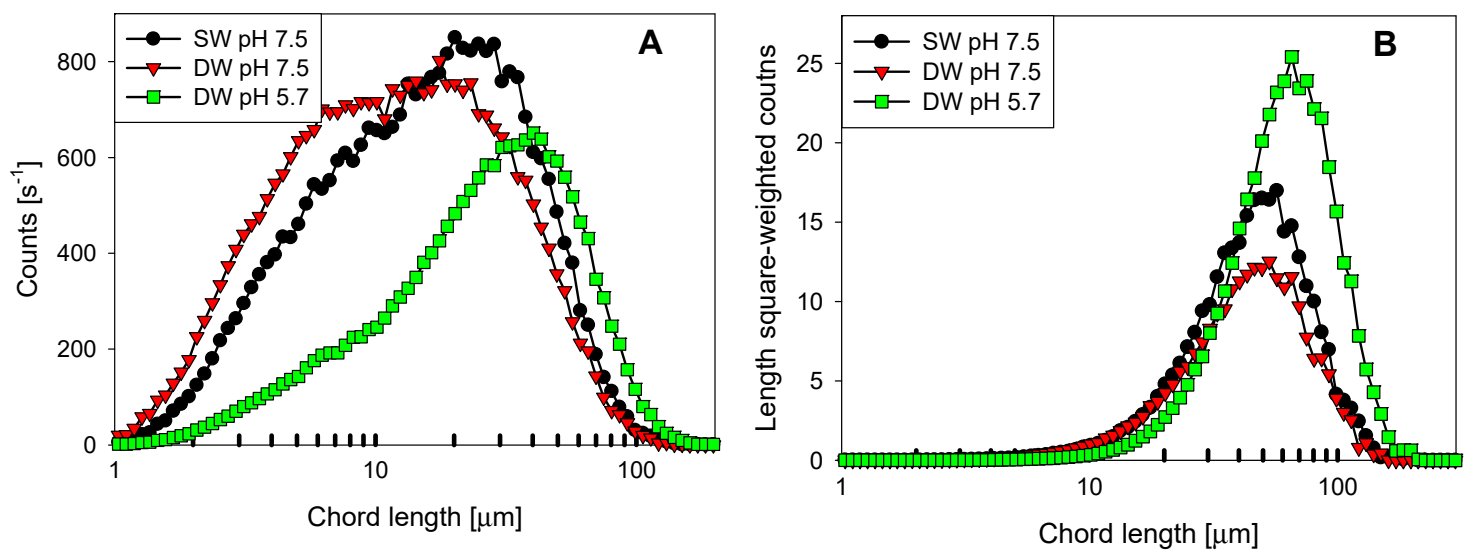

Figure 5. Chord length distribution (CLD) for untreated kaolin suspensions prepared at 7 wt. \% in distilled water (pH 5.7 and pH 7.5) and seawater (pH 7.5). (A) Unweighted CLD, (B) Squareweighted CLD.

The onset of fine particle aggregation would typically be expected to induce a shift to the right in both CLDs, as well as a loss in unweighted peak height and an increment in the volume-weighted peak height [33]. A shift to larger aggregate size appeared in both series of distributions ongoing from DW to SW because the high salinity of seawater reduced the magnitude of zeta potential from $-41 \mathrm{mV}$ to $-5 \mathrm{mV}$ (Figure 6), which contributed to particle coagulation. This change in aggregation may have been caused by the additional counterions in seawater-especially sodium, magnesium, and calcium - which adhered to the clay faces and reduced the magnitude of the electrostatic force that would typically dominate the interactions at $\mathrm{pH} 7.5$ in freshwater [34]. According to our previous study, the principal cation that adheres to the surface of the kaolin is magnesium [35], which, due to its divalent character, is particularly effective in neutralizing anionic surfaces [36].

The shift to larger chord length observed in the FBRM data may be considered an indication of increased fine particle aggregation. There were many submicron particles in the clay sample, but the FBRM did not measure these. When these particles aggregated-with each other or by joining existing aggregates-there was increase of chords measured by the lowest chord length channels of the instrument, which lowered the mean and median of the unweighted CLDs. This highlights the importance of examining the unweighted and volume-weighted CLDs, because the aggregation of many small submicron particles may go undetected in the FBRM data. For distilled water, the shift in the unweighted distribution (Figure 5A) and square-weighted distribution (Figure 5B), when lowering from $\mathrm{pH} 7.5$ to $\mathrm{pH}$ 5.7, is a clear indication of aggregation. This degree of aggregation was not expected from the analysis of zeta potential because the kaolin particles had a value of $-30 \mathrm{mV}$ in DW, which was substantially more significant than the $-5 \mathrm{mV}$ obtained in SW. However, the increased aggregation may be explained by the differentiation of electrical charge among faces and edges at $\mathrm{pH} 5.7$ [30]. Caution should be taken, as the zeta potential is only a global indicator of the charge on the entire surface-it does not differentiate the heterogeneities that occur in clays (edges and faces). This $\mathrm{pH}$ 
promotes a house-of-cards type of aggregation caused by electrostatic attraction of primary particles to a greater extent than that observed in seawater.

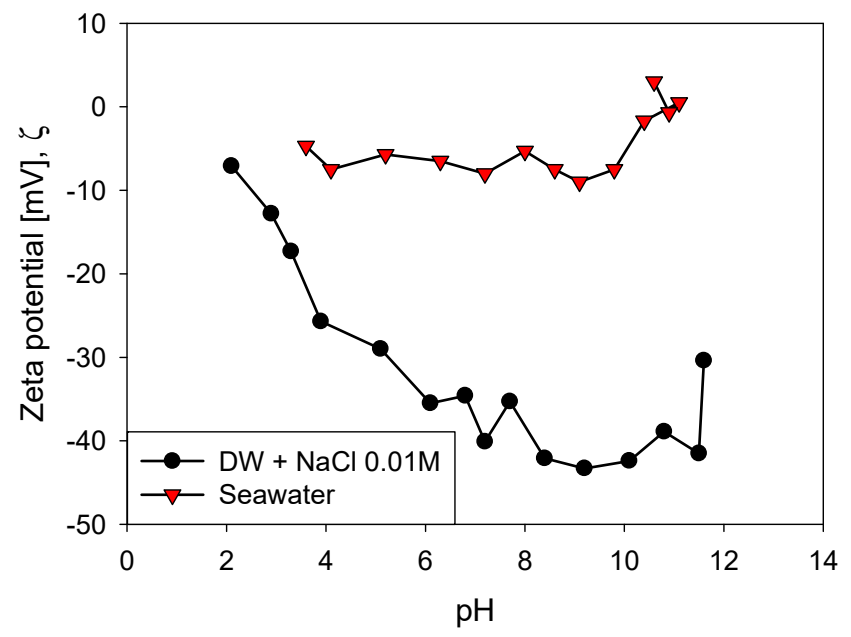

Figure 6. Zeta potential for kaolin particles in seawater and distilled water with sodium chloride $0.01 \mathrm{M}$.

\subsection{Supernatant Analysis}

The OBS of the supernatant was measured $2.5 \mathrm{~h}$ after flocculation. In Figure 7 , the mean scattering, $\mathrm{F}_{\text {mean }}$ of the supernatant is plotted as a function of polymer dosage for two different polymers (A100 and $\mathrm{A} 150 \mathrm{HMW}$ ) applied to kaolin suspensions prepared in freshwater and seawater at $\mathrm{pH} 5.7$ and $\mathrm{pH}$ 7.5. A lower $F_{\text {mean }}$ value of the supernatant is associated with a lower solids content, so it may be used as an indicator of the effectiveness of flocculation if improving the quality of recovered water is sought.

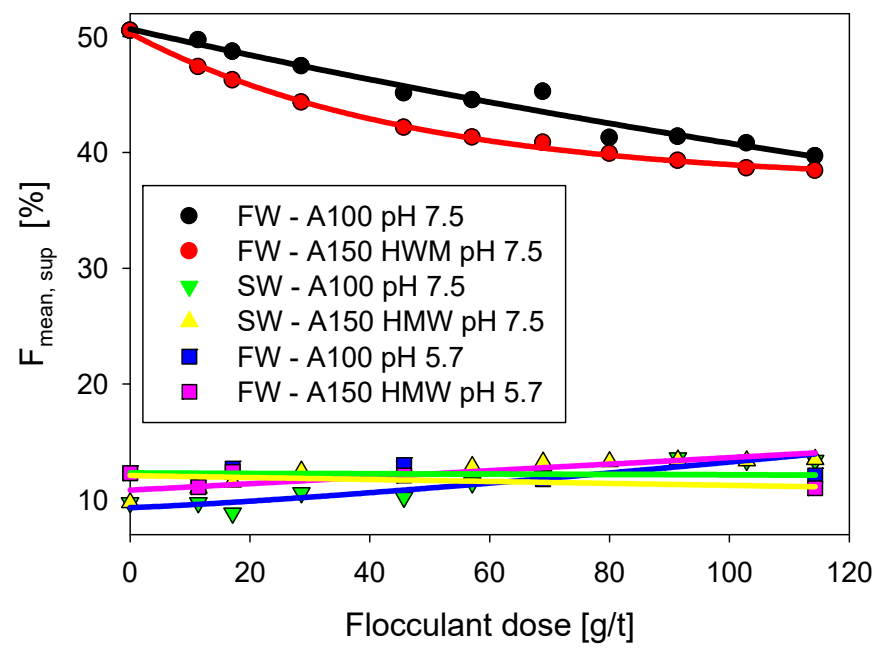

Figure 7. Signal values of $F_{\text {mean }}(\%)$ for supernatant liquid of kaolin suspensions $7 \mathrm{wt}$ \% flocculated with A150 HMW or A100 in three conditions: (i) Distilled water $(\mathrm{NaCl} 0.01 \mathrm{M})$ at $\mathrm{pH} 7.5$, (ii) seawater at $\mathrm{pH} 7.5$, and (iii) distilled water $(\mathrm{NaCl} 0.01 \mathrm{M})$ at $\mathrm{pH} 5.7$.

In distilled water, the results differed radically depending on the $\mathrm{pH}$. At $\mathrm{pH} 5.7$, the $\mathrm{F}_{\text {mean }}$ value did not exceed $15 \%$, regardless of flocculant type or dose, but at $\mathrm{pH} 7.5$, the $\mathrm{F}_{\text {mean }}$ started at $50 \%$ when no polymer was applied, then decreased to around $40 \%$ at the highest polymer dose applied. The higher values obtained at a higher $\mathrm{pH}$ are an indication that there was a greater amount of suspended solids at $\mathrm{pH}$ 7.5. Using the sample-drying method, it was determined that the suspended solids for the unflocculated sample after $2.5 \mathrm{~h}$ of sedimentation was $0.08 \mathrm{~g} / \mathrm{L}$ for $\mathrm{pH} 5.7$ and $0.51 \mathrm{~g} / \mathrm{L}$ for 
$\mathrm{pH}$ 7. This increase in unsettled solids seems to be related to the extent of aggregation in the untreated samples. The zeta potential and FBRM probe measurements suggests that coagulation likely occurred to a greater extent in seawater. Also, the higher electrostatic repulsion of clay at high $\mathrm{pH}$ generated dispersion, with a large amount of slow-settling particles (mean unweighted chord length, DW pH 5.7: $36(\mu \mathrm{m})$, DW pH 7.5: $14(\mu \mathrm{m}))$.

This difference in supernatant clarity and zeta potential at $\mathrm{pH} 5.7$ and $\mathrm{pH} 7.5$ in clay suspensions helps to explain the significant problem in the metallic mining industry, where the quality of the recovered water from thickeners may be suboptimal [26]. In many cases, it is mandatory to use additional reagents, like coagulants or polymers of low molecular weight, which can be selective to the fine material, either by neutralizing the anionic charges or forming electrostatic patch that bridge the small particles [37]. However, at pH 5.7, there was a marked difference between the charge of the positively charged edges and the negatively charged faces of the clay [30]. This led to a high particle aggregation before the addition of flocculant, reducing the amount of unflocculated fine material that remained in the supernatant.

In seawater at $\mathrm{pH} 7.5$, the $\mathrm{F}_{\text {mean }}$ started around $10 \%(0.09 \mathrm{~g} / \mathrm{L})$, which was much lower than the value in distilled water $(0.51 \mathrm{~g} / \mathrm{L})$. An explanation for this observation is that there was particle pre-agglomeration in the seawater samples that was promoted by compression of the electrical double layer [36]. From the FBRM results, the remaining particles in the solution (Figure 7) showed a good relationship with the unweighted chord length (Figure 5A), which, as stated above, was sensitive to fine mineral particles that would be present to a greater extent in the supernatant (mean unweighted chord length, DW pH 7.5: $25(\mu \mathrm{m}), \mathrm{DW}$ pH 7.5: $14(\mu \mathrm{m})$ ). These results suggest that the type and dose of flocculant do not play a significant role in the $F_{\text {mean }}$ value, especially in seawater.

\subsection{Sediment Solid Concentration}

The underflow solids concentration is a relevant parameter for thickening operations because it indicates how much water was extracted from the slurry and partially determines the approaches that may be adopted for tailings deposition [38]. Figure 8 describes the solid sediment concentration after $2.5 \mathrm{~h}$ of settling, determined by the mass balance which considered that all the particles were contained in the sediment. At the same time, the supernatant was pure liquid. The assumption is acceptable, since when measuring the maximum amount of suspended solids, it did not exceed $0.5 \mathrm{~g} / \mathrm{L}$ (less than $0.5 \%$ of the initial mass). The calculation requires the initial weight of particles and the geometry of the vessel. The height of the sediment was obtained through the OBS signal, since there was a marked transition when the mudline was found. The studied variables are the same as those addressed in Section 3.2, including the type and dose of flocculant, type of water, and $\mathrm{pH}$. The outcomes show that the initial aggregation state of clay particles before flocculation is a strong indicator of the aggregation state of the sediment.

When no flocculant was added, the sediment generated in $0.01 \mathrm{M} \mathrm{NaCl}$ at $\mathrm{pH} 7.5$ gave a solids percentage of $60 \mathrm{wt}$. \%, while it was $35 \mathrm{wt}$. \% for the slurry prepared at $0.01 \mathrm{M} \mathrm{NaCl}$ at pH 5.7. This behavior may reflect the porosity of the aggregates that made up the sediment: The higher aggregation of particles at $\mathrm{pH} 5.7$ was due to face-edge bonds and generated structures with lower porosity than particles dispersed at $\mathrm{pH}$ 7.3. Deng and Davè [39] found that when aggregates are produced at a higher rate, they grow irregularly, resulting in lower fractal dimensions. After the addition of the flocculant, there was a decline in the solid concentration, which was the result of the formation of large porous aggregates [40]. Therefore, it is expected that for a higher dosage, the sediment concentration would be lower. The same trend was found by MacIver and Pawlik [19], who studied the flocculation of kaolin particles using a nonionic polyacrylamide. Regarding flocculant type, the lower degree of anionicity polymer A100 generated a higher concentration of solids in the sediment than the higher degree of anionicity polymer, A150 HMW, at both pHs. It is suggested that the higher degree of anionicity caused a greater electrostatic repulsion between the polymer and kaolinite surface, which allowed the polymer molecules to take on an extended conformation that 
led to the formation of sizeable open structure flocs by the hydrogen bonds that linked the carbonyl groups of the polymers and the hydroxyl groups on the edges of the clay particles [41]. Nasser and James [42] found a similar phenomenon in their study of adsorption polyacrylamides on kaolinite.

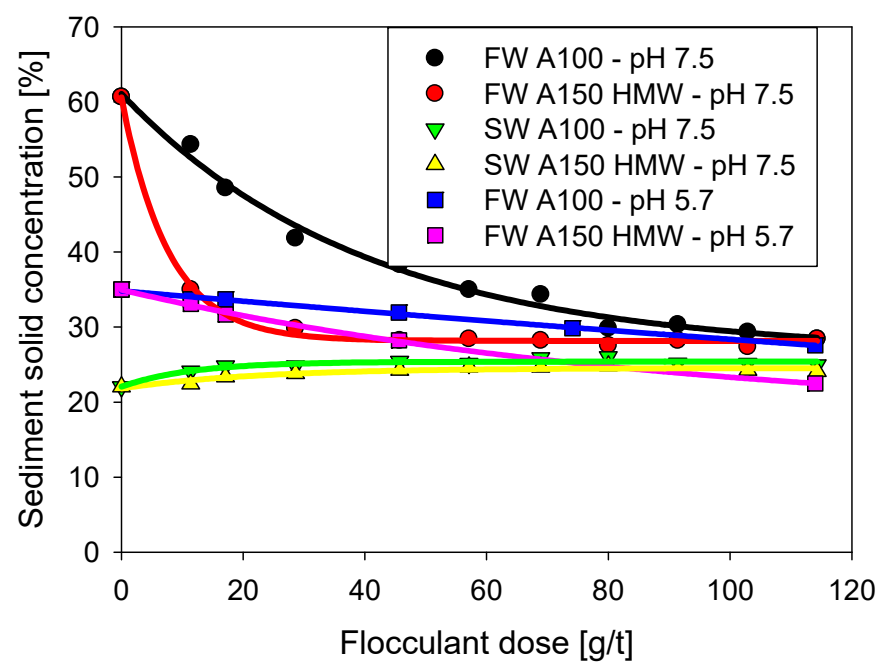

Figure 8. Solid concentration (wt. \%) kaolin sediments generated by settling of flocculated slurries with A150 HMW or A100 in three conditions: (i) Distilled water ( $\mathrm{NaCl} 0.01 \mathrm{M})$ at $\mathrm{pH} 7.5$, (ii) seawater at $\mathrm{pH} 7.5$, and (iii) distilled water $(\mathrm{NaCl} 0.01 \mathrm{M})$ at $\mathrm{pH}$ 5.7. Flocculation time: $2.5 \mathrm{~h}$.

In seawater, sediments with lower solid concentration were found, 22 wt. \%, with no significant change regarding the dose and type of flocculant. In a saline medium, the polymers were coiled to a greater extent than in fresh or distilled water, which decreased their ability to form polymeric bridges between particles. On the other hand, the presence of cations reduced electrostatic repulsion between anionic flocculant groups and particles that may support the flocculation [12].

\subsection{Flocculation Performance: Freshwater vs Seawater}

This section compares the performance of flocculants in distilled water and seawater at $\mathrm{pH}$ 7.5. The $F_{\text {rms }}$ values may be used as an indication of flocculation performance. In Figure 9, the $F_{\text {rms }}$ values for each condition are directly compared with the sediment volume to give an appreciation of the significance of the $\mathrm{F}_{\mathrm{rms}}$ values. With no flocculant added, in distilled water, the kaolin particles had a high electrostatic repulsion, as the zeta potential was near to $-40 \mathrm{mV}$. From the OBS data, the $\mathrm{F}_{\mathrm{rms}}$ value was close to zero, which indicates a minimal amount of aggregation, as shown in Figure 9A. However, in seawater, the ionic cloud was compressed (at a zeta potential of $-5 \mathrm{mV}$ ), reducing the $F_{\text {mean }}$ of the supernatant, which is an indication of improved flocculation performance. The $F_{\text {rms }}$ value of $0.2 \%$ suggests a better degree of aggregation, which was also related to a notable increase in the sediment's volume. The highest state of aggregation generated a volume of $8 \mathrm{~mm}^{3}$ in seawater, while in distilled water $(0.01 \mathrm{M} \mathrm{NaCl})$, it was only $1.5 \mathrm{~mm}^{3}$ (Figure $9 \mathrm{~B}$ ). Interestingly, the $\mathrm{F}_{\text {mean }}$ of the OBS measured from the supernatant may be correlated with the unweighted chord length (Figure 5A), while the aggregation degree in the sediment $\left(\mathrm{F}_{\mathrm{rms}}\right)$, correlated well with the peak magnitude for the square-weighted chord length (Figure 5B), which amplified its sensitivity to coarse aggregates. 

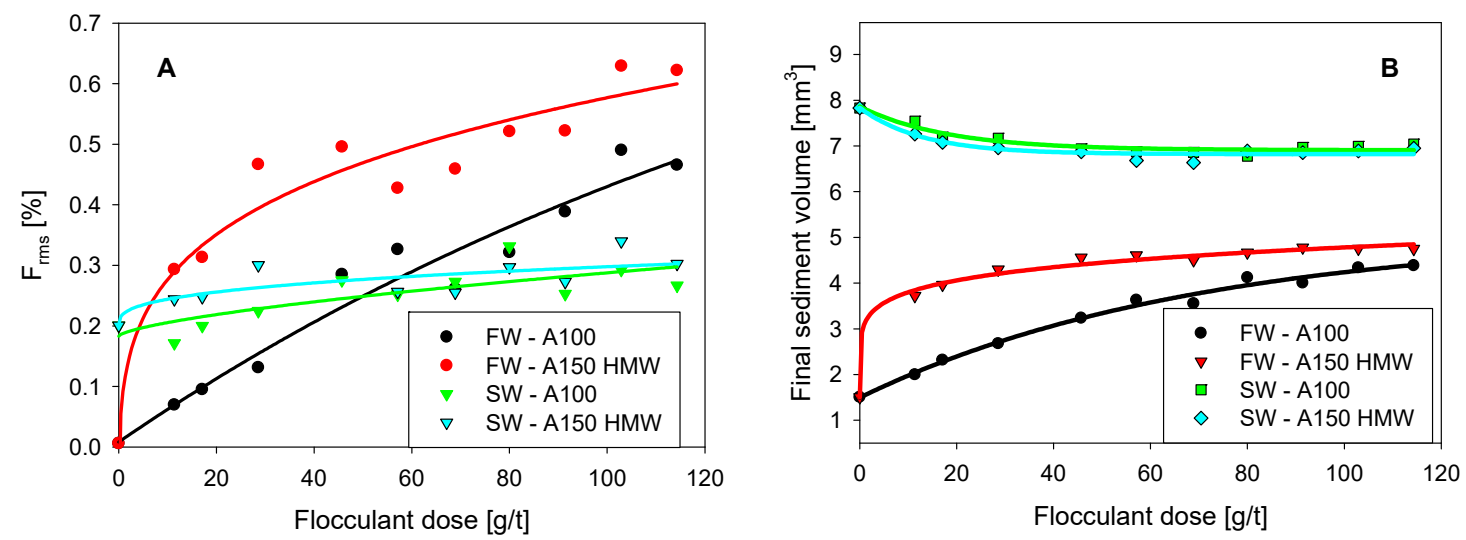

Figure 9. (A) Signal values $F_{r m s}$ and (B) final sediment volume at varied flocculant dose (A150 HMW and $\mathrm{A} 100)$ in the settled bed at $\mathrm{pH} 7.5$ for distilled water (FW) and seawater (SW).

The use of OBS suggests that the flocculation performance of kaolin slurries was better in seawater than in distilled water for low flocculant doses (Figure 5A). However, the $\mathrm{F}_{\text {rms }}$ signal seemed to underestimate the flocculation extent in seawater, since some works have reported a different course. For example, Ji et al. [9] analyzed a tailing from Teck Resources and compared sedimentation in freshwater and saline water. The saline water produced the best performance for the three anionic flocculants tested, and the authors concluded that the reduced electrostatic repulsion in the saline environment contributed to increase polymeric bridging of the flocculant with the mineral surfaces. However, the saline medium used by Ji et al. was only half the salinity of seawater, whereas we used seawater at its undiluted ionic strength in our study. The ionic strength of freshwater in the study by Ji et al. was low-the main element was $\mathrm{Na}^{+}$at a concentration of $141 \mathrm{ppm}$. However, to obtain a good performance of anionic polyelectrolytes, a degree of salinity is necessarily required [13], so it is anticipated that Ji et al. would have obtained a different flocculation result in freshwater. In undiluted seawater, the polymer's capacity was limited by the coiling of their chains, which produced smaller aggregates and a less pronounced $F_{\text {rms }}$ value with an increased polymer dose. The same trend could be anticipated in the volume of the sediment that presented a subtle variation concerning the dosage of the polymer. Whereas the $\mathrm{F}_{\mathrm{rms}}$ ranged from $0.2 \%$ (without flocculant) to $0.25 \%$ ( $115 \mathrm{~g} / \mathrm{ton}$ ), the volume of the sediment dropped from $8 \mathrm{~mm}^{3}$ to $7 \mathrm{~mm}^{3}$, respectively. The impact of the physicochemical properties of the polyelectrolyte are most significant in the low salinity system. Considering A150 HMW, which had a higher charge density, the $\mathrm{F}_{\text {rms }}$ value increased from approximately 0 to $0.6 \%$ after applying $115 \mathrm{~g} / \mathrm{t}$, while A100 achieved $0.45 \%$. The difference agrees with the response of the sediment volume, where a better aggregation state led to the sediment of higher volume. In this case, the sediment increased from $1.5 \mathrm{~mm}^{3}$ to $4.9 \mathrm{~mm}^{3}$ with $115 \mathrm{~g}$ ton of A150 HMW, while with A100, it achieved $4.3 \mathrm{~mm}^{3}$. Lee et al. [43] noted that polyacrylamide adsorption on the kaolinite surface occurs mainly on the broken bonds of the aluminol (Al-OH) and silanol $(\mathrm{Si}-\mathrm{OH})$ groups through hydrogen bonds. However, the electrostatic repulsion between the negative charges of the flocculant with the particle's surface reduced the performance of the polymer. Then, the adsorption was more significant after increasing the salinity, since the cations that came from the electrolytes formed an additional cationic bond. With increased polymer dose, the kaolin suspension prepared with distilled water $(0.01 \mathrm{M} \mathrm{NaCl})$, especially the A150 HMW polymer, exhibited the greatest aggregation. When the flocculant had a greater ionic charge and took on an extended conformation in solution, the particle flocculation had a greater sensitivity to dosing, which was reflected in a lower $F_{\text {mean }}$ in the supernatant (Figure 7) and higher value of $\mathrm{F}_{\mathrm{rms}}$ in sediments (Figure 9A). These outcomes are attractive as they exhibit the use of OBS as an effective indicator of the flocculation degree of a material, especially in conditions that are challenging to obtain as it would be in a continuous process. 


\section{Conclusions}

An experimental strategy that considered optical backscattering response was used to evaluate the effect of seawater on kaolin flocculation, focusing on the aggregation state and sediment concentration. Emphasis was placed on the type of flocculant, the flocculant dose, type of water, and $\mathrm{pH}$. The quality of the supernatant water, described by backscattering flux, is fundamentally linked to the precoagulation state of particles before adding flocculant. The $\mathrm{pH}$, flocculant type, and salinity had a greater impact on the flocculation result than the flocculant dosage. The results were especially sensitive to the presence of fine material, which was detected through the FBRM unweighted chord length distribution. The higher kaolin aggregation occurred in distilled water $(0.01 \mathrm{M} \mathrm{NaCl})$ at $\mathrm{pH} 5.7$ as a product of electrostatic attraction between positively charged edges and negatively charged faces, and in seawater at $\mathrm{pH} 7.5$ by the compression of the electrical double layer.

The sediments formed in distilled water at $\mathrm{pH} 7.5$ achieved a solids percentage of $60 \mathrm{wt}$. \%, while the pulp prepared at $\mathrm{pH} 5.7$ presented a solids percentage of $35 \mathrm{wt}$. \%. This behavior reflects the porosity of the aggregates that make up the sediment. The higher aggregation of the particles at $\mathrm{pH}$ 5.7 due to face-edge bonds generated structures of a lower porosity than the particles dispersed at $\mathrm{pH}$ 7.3. After adding flocculant, there was a decay in the concentration of solids, which resulted from the formation of large porous aggregates, similar to what happened in seawater. When no flocculant was added, the suspension settled into a low solids content sediment with a high $F_{\text {rms }}$ value and sediment volume. This is an indication that there was stronger coagulation in seawater, which was also observed in the FBRM data. Interestingly, the degree of aggregation in the sediments was linked to the square-weighted chord length distribution, which is more sensitive to coarse aggregates than fine particles. The coiled state of the flocculants in seawater caused the behaviors to be similar, regardless of the polymer used. However, the situation differed in a system with low salinity $(0.01 \mathrm{M} \mathrm{NaCl}), \mathrm{where}$ the type of reagent generated significant influence on distilled water. The A150 HMW polymer was more efficient than A100 polymer. The A150 HMW polymer has a higher ionic charge and extension in solution, so the particles flocculation presented a higher sensitivity to dosing, which, in general, reflected a higher value of sediment $F_{\text {rms }}$ and lower $F_{\text {mean }}$ of the supernatant.

Author Contributions: Conceptualization, R.I.J.; Data curation, M.J., M.R.M. and N.T.; Formal analysis, R.I.J., M.R.M.; Writing—original draft, R.I.J., M.J.; Writing—review \& editing, M.P., M.R.M. and P.R. All authors have read and agreed to the published version of the manuscript.

Funding: This research was funded by MINEDUC-UA project, code ANT 1855; Anid Fondecyt 11171036, and Centro CRHIAM Project Anid/Fondap/15130015

Acknowledgments: Ricardo I. Jeldres thanks MINEDUC-UA project, code ANT 1855; Anid Fondecyt 11171036; and Centro CRHIAM Project Anid/Fondap/15130015. Pedro Robles thanks the Pontificia Universidad Católica de Valparaíso for the support provided.

Conflicts of Interest: The authors declare they have no conflict of interest.

\section{References}

1. Scott, K.J. Experimental study of continuous thickening of a flocculated silica slurry. Ind. Eng. Chem. Fundam. 1968, 7, 582-595. [CrossRef]

2. Scott, K.J. Continuous thickening of flocculated suspensions. Comparison with batch settling tests and effects of floc compression using pyrophyllite pulp. Ind. Eng. Chem. Fundam. 1970, 9, 422-427. [CrossRef]

3. Cisternas, L.A.; Gálvez, E.D. The use of seawater in mining. Miner. Process. Extr. Metall. Rev. 2018, 39, 18-33. [CrossRef]

4. Jeldres, R.I.; Forbes, L.; Cisternas, L.A. Effect of seawater on sulfide ore flotation: A review. Miner. Process. Extr. Metall. Rev. 2016, 37, 369-384. [CrossRef]

5. Castro, S. Physico-chemical factors in flotation of $\mathrm{Cu}-\mathrm{Mo}-\mathrm{Fe}$ ores with seawater: A critical review. Physicochem. Probl. Miner. Process. 2018, 54, 1223-1236. [CrossRef]

6. Franks, G.V. Zeta potentials and yield stresses of silica suspensions in concentrated monovalent electrolytes: Isoelectric point shift and additional attraction. J. Colloid Interface Sci. 2002, 249, 44-51. [CrossRef] 
7. Jeldres, R.I.; Piceros, E.C.; Leiva, W.H.; Toledo, P.G.; Quezada, G.R.; Robles, P.A.; Valenzuela, J. Analysis of silica pulp viscoelasticity in saline media: The effect of cation size. Minerals 2019, 9, 1-15. [CrossRef]

8. Liu, D.; Edraki, M.; Berry, L. Investigating the settling behaviour of saline tailing suspensions using kaolinite, bentonite, and illite clay minerals. Powder Technol. 2018, 326, 228-236. [CrossRef]

9. Ji, Y.; Lu, Q.; Liu, Q.; Zeng, H. Effect of solution salinity on settling of mineral tailings by polymer flocculants. Colloids Surf. A Physicochem. Eng. Asp. 2013, 430, 29-38. [CrossRef]

10. Shaikh, S.M.R.; Nasser, M.S.; Magzoub, M.; Benamor, A.; Hussein, I.A.; El-Naas, M.H.; Qiblawey, H. Effect of electrolytes on electrokinetics and flocculation behavior of bentonite-polyacrylamide dispersions. Appl. Clay Sci. 2018, 158, 46-54. [CrossRef]

11. Costine, A.; Cox, J.; Travaglini, S.; Lubansky, A.; Fawell, P.; Misslitz, H. Variations in the molecular weight response of anionic polyacrylamides under different flocculation conditions. Chem. Eng. Sci. 2018, 176, 127-138. [CrossRef]

12. Jeldres, R.I.; Piceros, E.C.; Leiva, W.H.; Toledo, P.G.; Herrera, N. Viscoelasticity and yielding properties of flocculated kaolinite sediments in saline water. Colloids Surf. A Physicochem. Eng. Asp. 2017, 529, 1009-1015. [CrossRef]

13. Quezada, G.R.; Jeldres, R.I.; Fawell, P.D.; Toledo, P.G. Use of molecular dynamics to study the conformation of an anionic polyelectrolyte in saline medium and its adsorption on a quartz surface. Miner. Eng. 2018, 129, 102-105. [CrossRef]

14. Jeldres, M.; Piceros, E.C.; Toro, N.; Robles, P.; Nieto, S.; Quezada, G.R.; Jeldres, R.I. Enhancing the sedimentation of clay-based tailings in seawater by magnesium removal treatment. Sep. Purif. Technol. 2020, 242, 116762. [CrossRef]

15. Concha, F.; Rulyov, N.N.; Laskowski, J.S. Settling velocities of particulate systems 18: Solid flux density determination by ultra-flocculation. Int. J. Miner. Process. 2012, 104-105, 53-57. [CrossRef]

16. Concha, F. Solid-Liquid Separation in the Mining Industry; Springer International Publishing: Basel, Switzerland, 2013; ISBN 3319024841.

17. Hunter, T.N.; Peakall, J.; Egarr, D.; Cowell, D.M.J.; Freear, S.; Tonge, A.S.; Horton, L.; Rice, H.P.; Smith, I.; Malone, K.; et al. Concentration profiling of a horizontal sedimentation tank utilising a bespoke acoustic backscatter array and CFD simulations. Chem. Eng. Sci. 2020, 218, 115560. [CrossRef]

18. Owen, A.T.; Fawell, P.D.; Swift, J.D.; Labbett, D.M.; Benn, F.A.; Farrow, J.B. Using turbulent pipe flow to study the factors affecting polymer-bridging flocculation of mineral systems. Int. J. Miner. Process. 2008, 87, 90-99. [CrossRef]

19. MacIver, M.R.; Pawlik, M. Measurement of optical backscattering height scans from flocculated mineral sediments. Colloids Surf. A Physicochem. Eng. Asp. 2017, 514, 38-46. [CrossRef]

20. Downing, J. Twenty-five years with OBS sensors: The good, the bad, and the ugly. Cont. Shelf Res. 2006, 26, 2299-2318. [CrossRef]

21. Bunt, J.A.C.; Larcombe, P.; Jago, C.F. Quantifying the response of optical backscatter devices and transmissometers to variations in suspended particulate matter. Cont. Shelf Res. 1999, 19, 1199-1220. [CrossRef]

22. Campbell, D.E.; Spinrad, R.W. The relationship between light attenuation and particle characteristics in a turbid estuary. Estuar. Coast. Shelf Sci. 1987, 25, 53-65. [CrossRef]

23. Chakraborti, R.K.; Gardner, K.H.; Atkinson, J.F.; Van Benschoten, J.E. Changes in fractal dimension during aggregation. Water Res. 2003, 37, 873-883. [CrossRef]

24. Peng, F.F.; Di, P. Effect of multivalent salts-calcium and aluminum on the flocculation of kaolin suspension with anionic polyacrylamide. J. Colloid Interface Sci. 1994, 164, 229-237. [CrossRef]

25. Jeldres, R.I.; Piceros, E.C.; Wong, L.; Leiva, W.H.; Herrera, N.; Toledo, P.G. Dynamic moduli of flocculated kaolinite sediments: effect of salinity, flocculant dose, and settling time. Colloid Polym. Sci. 2018, 296, 1935-1943. [CrossRef]

26. Castillo, C.; Ihle, C.F.; Jeldres, R.I. Chemometric optimisation of a copper sulphide tailings flocculation process in the presence of clays. Minerals 2019, 9, 582. [CrossRef]

27. Quezada, G.R.; Ramos, J.; Jeldres, R.I.; Robles, P.; Toledo, P.G. Analysis of the flocculation process of fine tailings particles in saltwater through a population balance model. Sep. Purif. Technol. 2019, 116319. [CrossRef] 
28. Jeldres, M.; Piceros, E.C.; Toro, N.; Torres, D.; Robles, P.; Leiva, W.H.; Jeldres, R.I. Copper tailing flocculation in seawater: Relating the yield stress with fractal aggregates at varied mixing conditions. Metals 2019, 9, 1295. [CrossRef]

29. Jeldres, M.; Piceros, E.; Robles, P.A.; Toro, N.; Jeldres, R.I. Viscoelasticity of quartz and kaolin slurries in seawater: Importance of magnesium precipitates. Metals 2019, 9, 1120. [CrossRef]

30. Zhou, Z.; Gunter, W.D. The nature of the surface charge of kaolinite. Clays Clay Miner. 1992, 40, 365-368. [CrossRef]

31. Grabsch, A.F.; Yahyaei, M.; Fawell, P.D. Number-sensitive particle size measurements for monitoring flocculation responses to different grinding conditions. Miner. Eng. 2020, 145. [CrossRef]

32. Arinaitwe, E.; Pawlik, M. A method for measuring the degree of anionicity of polyacrylamide-based flocculants. Int. J. Miner. Process. 2009, 91, 50-54. [CrossRef]

33. Kyoda, Y.; Costine, A.D.; Fawell, P.D.; Bellwood, J.; Das, G.K. Using focused beam reflectance measurement (FBRM) to monitor aggregate structures formed in flocculated clay suspensions. Miner. Eng. 2019, 138, 148-160. [CrossRef]

34. Herrington, T.M.; Clarke, A.Q.; Watts, J.C. The surface charge of kaolin. Colloids Surf. 1992, 68, 161-169. [CrossRef]

35. Robles, P.; Piceros, E.; Leiva, W.H.; Valenzuela, J.; Toro, N.; Jeldres, R.I. Analysis of sodium polyacrylate as a rheological modifier for kaolin suspensions in seawater. Appl. Clay Sci. 2019, 183, 105328. [CrossRef]

36. Israelachvili, J. Intermolecular and Surface Forces, 3rd ed.; Elsevier: Santa Barbara, CA, USA, 2011; ISBN 9780123919274.

37. Yu, W.; Gregory, J.; Campos, L.; Li, G. The role of mixing conditions on floc growth, breakage and re-growth. Chem. Eng. J. 2011, 171, 425-430. [CrossRef]

38. Gladman, B.J.; Usher, S.P.; Scales, P.J. Understanding the thickening process. In Paste; Jewell, R.J., Lawson, S., Newman, P., Eds.; Australian Centre for Geomechanics: Perth, Australia, 2016; pp. 5-12.

39. Deng, X.; Davé, R.N. Breakage of fractal agglomerates. Chem. Eng. Sci. 2017, 161, 117-126. [CrossRef]

40. Benn, F.A.; Fawell, P.D.; Halewood, J.; Austin, P.J.; Costine, A.D.; Jones, W.G.; Francis, N.S.; Druett, D.C.; Lester, D. Sedimentation and consolidation of different density aggregates formed by polymer-bridging flocculation. Chem. Eng. Sci. 2018, 184, 111-125. [CrossRef]

41. Kohl, R.A.; Taylor, S.A. Hydrogen bonding between the carbonyl group and wyoming bentonite. Soil Sci. 1961, 91, 223-227. [CrossRef]

42. Nasser, M.S.; James, A.E. Effect of polyacrylamide polymers on floc size and rheological behaviour of kaolinite suspensions. Colloids Surf. A Physicochem. Eng. Asp. 2007, 301, 311-322. [CrossRef]

43. Lee, L.T.; Rahbari, R.; Lecourtier, J.; Chauveteau, G. Adsorption of polyacrylamides on the different faces of kaolinites. J. Colloid Interface Sci. 1991, 147, 351-357. [CrossRef] 